\title{
In Conversation with David Clark: Part II
}

The following is the second part of Brian Barraclough's interview with Dr David Clark. Part I appeared in the March Bulletin.

BB And what were you doing during these later years?

DC In the mid-seventies I reviewed my work and took responsibility for the long-term patients. We developed the Cambridge Psychiatric Rehabilitation Service which was described in an article in the Lancet recently. "In the last ten years, I built up a service which supports the long-term patients out in the community. When I first met the long-term patients they were locked up, consigned to the back wards where their only job was to live as long as they chose, and then to die and to be buried in the asylum graveyard. There they were, herded into these warehouses, stultified by the way we handled them. We showed that with freedom, activity, responsibility, they could live a very much better life in the hospital. We then saw many could move out of the hospital; and in the sixties the people who moved out of the mental hospitals went off and we never saw them again. They managed perfectly well, having recovered first from the psychosis that took them to hospital, and then from the institutionalisation which kept them there.

BB Do you think drugs played much of a part?

DC Yes. They relieved tension, suppressed some symptoms, and made it easier to try things out. By the seventies, we were working with people more impaired by their disorders and with residual deficits. How much they could do, we've slowly been exploring. And we've been forced to face the facts that despite all our modern drugs, and all our modern skills, there are still people who become long-term hospital in-patients. The number is probably not as great as it was, but there are a few every year, graduating to 'long-term status'. We showed it was 15 or 20 people every year in Cambridgeshire from a catchment population of about half a million.

In the past ten years in Cambridge we have been developing our psychiatric rehabilitation service. Most of the long-term patients are living out of hospital. Of 400 long-term patients, only 150 are on wards at Fulbourn, and only 70 in fully staffed wards; the others are in hostel wards, half-way houses, sheltered accommodation, and group homes. With a network of facilities, sheltered living daytime activities, skilled and devoted staff available to visit, support and help through difficulties, most long-term patients do not need to be in a custodial institution.
DC Difficult to tell. Some are youngish and disturbed, and there is a reasonable chance that by mid-life they may be quiet and be able to move out. Others have multiple disabilities, for instance, a psychosis and a severe heart condition, or hemiplegic and simple minded, so that they require physical nursing and psychiatric nursing. How many people require residence in a fully staffed psychiatric institution is not yet clear. The number is uncertain, but small.

BB Is a mental hospital necessary for them?

DC No.

BB You're looking forward to the demolition of Fulbourn?

DC Not necessarily. The site so near the city may be useful, some of the buildings are still good. But we must avoid another vast human warehouse, holding hundreds of people in impoverished and authoritarian conditions.

BB Can a psychiatric rehabilitation service be run from a DGH base, without mental hospital back up?

DC I should think so, although I haven't seen it done. However, doctors, responsible for acute patients as well as long-term, will inevitably neglect the long-term patients. They can't help it. Acute patients present acute problems which must be attended to at once; the others are forgotten, and then things go wrong. There will always have to be specialised institutions for security patients. In Fulbourn we were able to contain and help people from security hospitals, but that would be difficult in a DGH.

BB Yes, impossible.

DC Oh well, I don't know ... difficult. It needs a lot more courage.

BB Do you think it necessary to have one consultant whose sole job it is to run the service for the longterm patient?

DC Much preferable. It is much better to have someone specialising, committing themselves. The problems of a long-term patient are very different from the issues that face a patient suffering from a short-term psychotic disorder. The problems of the long-term patient are often more social and educational than medical.

BB Could we come back to your psychiatric training, that prepared you for this task.

DC Well, I can't say that my psychiatric training prepared me for the task of opening up the hospital, or for running therapeutic communities, or a rehabilitation service. It trained me to be a 1950 s psychiatrist, not much else.

All we were taught, especially at the Maudsley, was individual-focused on the individual's mental 
state, the individual's physical state, the individual's psychopathology. It was only later, gradually, and mostly by myself that I learned something of the social factors in breakdown and in recovery.

BB So whom did you learn your psychiatry from?

DC At the Maudsley in 1950-53, Aubrey Lewis was the dominating figure. I worked on the Professorial Unit for a year. Then I went as Senior Registrar to out-patients, where by good fortune I was told to work for Dr Foulkes, from whom I learned a great deal.

D. K. Henderson was a man of warmth, charm, and ability. At the time I was with him in the late 1940s he was holding prodigious, almost ludicrous power. He was the Professor of Psychiatry, superintendent of three hospitals, and ran the largest private practice in Scotland. So he didn't have enough time for any of them. He had an idiosyncratic way of teaching, but one learned a lot with him because he gave you a job to do and trusted you to get on with it. When one went to him in despair, his comment always was, 'Well, you'll just have to do the best you can'. If you went wrong, he told you. He brought out the best by challenging you and supporting you. One always knew that whatever happened DK would be there and back you. I learned from DK how to help people grow, and from Aubrey Lewis, how not to help people to grow. Aubrey was a man of brilliance, of immense erudition, but the effect that he had on junior doctors was malignant. He terrified them. The only thing many of them learned at the Maudsley was to avoid being cut to pieces. Many of us learned how to avoid it-feed him a juicy fragment, and provided he thought he had scored off you he would leave you alone. But if a junior doctor tried to defend himself, Aubrey would go on and on until he had reduced the registrar to a quivering heap. I remember him saying to a group of senior registrars, 'I can't understand why the registrars are so frightened of me; I'm only trying to help them to clarify their thinking. It is the Socratic method.' We came to understand why the Athenians put Socrates to death!

BB You must have some good things to say about Lewis's achievements?

DC Of course, he did much that was valuable. We are constantly being told about it! He ruled the postwar Maudsley firmly, he held it together, he won it the resources it needed, he fought for psychiatry amongst the physicians and surgeons and politicians. He lectured and wrote and summarised and reviewed endlessly, and was a powerful intellectual force for clear logical thinking and erudite writing. He ruled the Maudsley with a rod of iron and his view of how a psychiatrist should be was enforced. A lot of good people came from the Maudsley, but that was because they were good people before they went there, rather than because of what Lewis did for them. People came out of the Maudsley able to quote references and argue, but they were often incapable of taking responsibility for a difficult patient or facing a really nasty problem. And as for handling a disturbed ward or a group of angry staff, they just hadn't a notion. To me, the Monday morning conference was one of the saddest things that happened at the Maudsley. I came down from Edinburgh and saw the eminent there, pretty well all the great names in British psychiatry. They sat like terrified rabbits while Aubrey seduced them into saying something and cut what they said to ribbons with his logic. He had them all there and demonstrated their impotence.

BB So you didn't like him?

DC Personally, I liked him a lot. I found him charming, courteous, kind and witty, once he had come to the conclusion you were all right. But I hated the way he ran the hospital.

BB What did he have to say about your going to Fulbourn?

DC He didn't try to dissuade me. I was told he wrote me a good reference. I think he felt I wasn't Maudsley material.

BB Still, he had you for three years. Can we return to Foulkes. What was his career?

DC Foulkes came from Frankfurt in 1933, a refugee from Nazism like Stengel and so many others. He was at first in Exeter, then in the Army at Northfield; after the war he was at Barts part-time and he had a private practice in Wimpole Street. He came to the Maudsley, as many psychotherapists did in those days, to spend a few years there. It was a hard experience. They had contact with the bright young trainees, but they had to operate in an uncongenial and hostile environment. I found in the Out-patient Department this nice, foreign gentleman who seemed puzzled about what was going on.

BB He certainly gave that impression.

DC I wanted to learn about group therapy, so started doing groups with him. As I struggled I found that a talk with Foulkes cleared my mind and I came to value my sessions with him. To my surprise I found after a year or so I was operating effectively as a group therapist. Clearly, l'd learned from him. Not until some years later did I realise just how much I learned from him and how good he was at allowing people to acquire insight. I kept in touch with him for the rest of his life through the Group Analytic Society.

BB Foulkes is credited with discovering group psychotherapy, is that correct?

DC Yes.

BB What did he discover? 
DC $\mathrm{He}$ had started experiments with seeing psychotherapy patients in groups.

BB For economy?

DC No, I think it was for theoretical reasons and research. He wondered where it would lead him.

BB Where?

DC First in Exeter, but then at Northfield, the military hospital, where he and a bunch of bright young psychiatrists used groups a lot. Then they went back to London, to the Tavistock for example, to develop their ideas. He developed his own brand of group analytic psychotherapy, and then over the next 30 years he continued probing, refining, examining and developing the technique.

BB So how did you learn to be a superintendent?

DC Mostly by doing the job-the best way to learn any job! But I was greatly helped by a course for superintendents run by the King Edward's Fund in 1957. I found myself for a month with Duncan McMillan, Rudolf Freudenberg and a number of others from whom I learned a lot. I learned most of all from Maxwell Jones. His Belmont Unit was at its most exciting and turbulent peak and he expounded his ideas of the therapeutic community with brilliance, charm and enthusiasm. I became a friend and have been learning from him ever since. I have reflected on what I said about Henderson, Lewis and Foulkes and how I learned from them. If I did anything and talked with any of them I thought to myself afterwards, 'Well, he's a wise man and I'm a fool'. But what came next was the difference. With Henderson I thought, 'Well, he's a wise man and I'm a fool, but strangely enough he seems to trust me to do a decent job, I'll try and do better next time.' After I had talked with Lewis I thought, 'Well, he's a wise man and I'm a fool, he's made me realise what a fool I am, I'll not get caught that way again.' And with Foulkes I used to think, 'Well, he's a wise man and I'm a fool, but he seems to think that I may be able to grasp this and I'm beginning to see something about what its about.' Three different ways of helping a student to learn and grow. Everybody has more capacity for growth than you think they have, and if you give them support and trust, challenge and opportunity, the most surprising people, the most psychotic patient, the most stubborn nurse, the most stupid registrar, will do far more than you ever thought they could.

BB You have been interested in therapeutic communities.

DC Yes. The therapeutic community has been the most important professional experience that l've had. My original concern was to make a better life for the pathetically imprisoned people. In doing so, I came to realise that the best ideas for changing things came from the grass roots, to begin with, from the nurses. Then I began to find ideas coming from the patients too. I realised that if you want to improve the life of people, one of the best things to do is to find out what they themselves actually want, rather than assuming that you know, and imposing it on them. So I started to listen to the patients and I realised that they had lots to say which was worth listening to. About ten years after I had been at Fulbourn I began to apply directly the ideas I picked up from Maxwell Jones. Maxwell Jones taught us to listen to the patients and then encourage them to tell one another about their problems. I found that if somebody can't understand why he is being detained on a Section, often other people who had been or were going to be detained, could explain it to them much better than I could. They would say, 'You're not fit to be running around loose just now, Dr Clark is quite right to put you on a Section.' There were occasions when the therapeutic community insisted I put someone on a Section, to protect them from themselves. I enjoyed this way of working, where the patients were doing so much of the work. My job was to authenticate and support them with my authority and prestige. I found this exciting, challenging, immensely worthwhile and I learned a lot. I have spent much time in the last twenty years, trying to understand the application of this to a psychiatric hospital and to other settings. I have helped to get therapeutic communities going in other settings, and have spent a lot of time working in the Association of Therapeutic Communities. If you have a residential institution containing disturbed people, a socio-therapeutic approach is the only one that has any future. One of the challenges for psychiatrists is how to learn to do this, despite their medical training with its authoritarian accent.

BB I believe you did quite a lot in the College at one time, and I believe you were the vice-chairman of the NAMH.

DC Yes I was-that was an interesting phase of my life. For a decade I moved amongst the mighty, I bowed to princesses, I hobnobbed with peers and MPs, and those who ruled and moved our land. And it was often exciting and exhilarating. I sat on committees and pondered great issues and passed resolutions, I would announce things in the press, appear on television, on the radio, and so on. I doubt how much value it had, although it was interesting to meet princesses, and very charming they were too. After a time, however, I began to ask myself, 'Is this doing the patients any good?' It wasn't, so after a time I pulled out of it.

BB What about the NAMH?

DC That was an interesting business. In the late sixties I was asked to help with the National Association for Mental Health. It was a delightful organisation, which enabled psychiatrists, social workers, MPs, peeresses, to work together with people of good will to encourage society as a whole to take a more 
enlightened and helpful view of the needs of the mentally ill and the mentally handicapped. A wonderful job was done from the time that they got it together in 1950 until about 1970. Then a new mood came. It wasn't only in the NAMH. It was general. There was emphasis on people's rights, rather than their welfare. There was a feeling against psychiatrists and psychiatry. Some was a just repayment for the arrogance that some of us had shown over the years, and some a reaction to disappointment that we'd failed to deliver the goods so exuberantly promised in the early ' 50 s when psychiatrists were saying that psychiatry would cure all mental disorder, abolish all suffering and bring wisdom to a discovered world. But it was all rather sad. NAMH became MIND, a civil rights, rather anti-psychiatric organisation, and I feit out of place. At that stage I stopped being involved on a national scale, but continued to work in a local mental health organisation in Cambridge.

BB How did that change in the NAMH occur?

DC I believe it corresponded with anti-psychiatric pressures in the country as a whole. If NAMH hadn't done it, some other organisation would have been set up to do it. NAMH continued to do a great deal of positive work all through the '70s, but the civil rights work brought conflict. Instead of cooperation between NAMH and the psychiatrists, there came hostility. This was also at the time when psychiatrists were moving away from co-operation with other professions and a general concern with mental health, and turning inward and trying to become more and more professional, medical, scientific.

BB You see the development of the College as part of the same process as the formation of MIND out of NAMH?

DC Yes. I was active in the Royal Medico-Psychological Association at the time the College was formed.

BB You were for it?

DC Yes. I was sad that it turned into a body more and more obsessed with examining and failing people, setting up more and more complicated examinations. The paralysing effect that the membership has had on the learning of young doctors is unfortunate. In the '50s and '60s the DPM was there and anybody who was any good got it. Now they are paralysed by the exam for years. The College seems to me now to be a much more inward looking body than the RMPA was in the '60s.

BB An academic department of psychiatry developed at Cambridge University in the 1970s. What effect did it have on Fulbourn Hospital?

DC Not very much. It's impact was not as damaging as the drying up of funds for development after 1974 and the paralysing effect of the progressive reorganisations. The Cambridge Health District has been in severe financial difficulties for the last 15 years because the New Addenbrooke's Hospital was never properly funded, so that what new money there was went to the exotic activities of Addenbrooke's, like kidney and heart and liver transplants. Psychiatry, especially the care of the long-term patients, got very little funds or attention.

The same shortages affected the new medical school. When Cambridge University belatedly decided in the late ' 60 s to have a medical school, they planned in the belief that the University would always have plenty of money and that the NHS would always have plenty of money, so that a new medical school could be built from those two sources. They did not realise that both lots of money ultimately came from the public purse; when the public purse ran dry in the mid-seventies both of the funds ran dry too. So the medical school has been terribly hard work for everybody. In the late 1960s, many of us had had great hopes of the new Clinical School and some, like Bernard Zeitlyn and I, spent years preparing for it. We had plans for an exciting curriculum using the ideas of Balint and Abercrombie, as at McMaster University.

BB Would you like to say something about your experience at Palo Alto?

DC In the United States there is a postgraduate centre for social scientists called the Centre for the Advanced Study of Behavioural Sciences. They like to have a few foreigners, a few psychiatrists, a few lawyers, a few historians, and people like that along for flavour. It's a wonderful place, in a most beautiful part of California. They bring you and your family from wherever you live in the world and pay your salary for a year, and provide a study and a secretary, and make no demands on you at all. It was a wonderful experience. When I went there I didn't believe I could write a book, but being amongst people, all of whom were writing books, I got down to it and I did get my first book done. The year I was there, Eric Erikson and Carl Roger were both Fellows and I got to know them both and learned much from them.

BB What did you think of Roger?

DC Delightful man, with the capacity to bring out the best in other people. One of the things that was most revealing to me about Carl was his opinion about book reviews. He said, 'I never do reviews. If you are required to do a review, you are required to think critically and spitefully about another person and I really didn't feel I wanted to spend my time doing that.' $\mathrm{He}$ is interested in helping other people discover what they can do, what their potentialities 
are, rather than pointing out to them their failings, weaknesses and incompetences.

BB And Erikson?

DC Eric was a different figure. A big man with a bright red face, a great halo of white hair, charming, erudite, stimulating. He used to reminisce about summer holidays with the Freud family. He would bubble off in all directions about anything and anybody. His talk is slightly easier to follow than his writings!

BB You have been a WHO adviser? I take it that your work at Fulbourn was the basis for your appointment.

DC Yes. People came to visit Fulbourn in the early days and some asked me to go to the States and lecture about what I had been doing. I saw unspeakable places there, infinitely worse than anything in Britain. I realised that though clinical psychiatry was the same in most countries, the services provided are very different. It seems to depend on the primary health care services of the country and the attitudes to mental disorder. I did one or two things for WHO. They asked me in 1967 to go to Japan for four months.

BB What was the point of going to Japan, from the Japanese point of view?

DC The Japanese psychiatric scene was changing rapidly, and they weren't sure if they had got it right. Immediately after the war, after the destruction of Japan by the Allies, most of the long-stay patients had died and there were hardly any institutions for the long-term patient.

In the early 1950 s there were 80,000 mental hospital beds, for 100 million Japanese people. Their advisers told them they must build up the number of mental institutions. So they did, but with private hospitals. When I went there in 1967 there were 130,000 beds and I found they were packed with patients, who were stuffed with largactil. The more patients a doctor got into the place, the more money he made. People were keen to get rid of their mad relatives so they readily certified them; the patients were full of largactil, so they didn't complain. There was little concern for the life of the long-term patients. I said to the Japanese, 'If you don't do something about it, then the numbers concerned will go up and up. In due course you'll have a horrible problem.'

BB To which Japanese people did you say this?

DC The government. I made a report to the Japanese government. It was known as the Clark Report, and it was discussed in the Japanese parliament and caused a hullabaloo at the time. It was regarded as a wildly radical document.

BB What did you recommend?

DC That they had to have rehabilitation services and an inspectorate for mental hospitals, that they should concentrate on getting people out of hospital rather than in. They did not do these things. As a result, the numbers went up. At the time our numbers were going down, the Japanese numbers were going up and by the mid-seventies, there were 300,000 mental hospital in-patients, 32 per 10,000 .

BB Do you think, in retrospect, that your report was a bit too much for them to digest in one go?

DC Yes. Giving advice to other countries is profoundly difficult. I had no beginning of an understanding of what it involved.

BB Is the Clark Report now in use?

DC It's in use. It's widely quoted and my books have been translated into Japanese and they're read there. I've been back several times.

BB And you've been to South America?

DC I was asked to go to Peru. Peruvians are charming people. They took quite a lot of notice of what we said. But their economic problems since have made it practically impossible. They did set up therapeutic communities in the Larco Herera Hospital. But it came to nothing because of their economic troubles.

Then I was asked to go to Argentina in 1968. A shattering experience. We were nearly thrown out of the country for preaching democracy! My wife said that she thought it would be a good idea if the nurses got themselves organised in the hospital. The medical superintendent banned her from entering the hospital again, saying, 'This is syndicalism and will not be allowed here!' I forced a formal apology (for the insult to my honour) from the Colonel in charge but was left with a strong distaste for military government of mental hospitals! That was during the military regime. They are doing better now, I believe.

The WHO later sent me to Poland. The Poles sent me a letter saying, 'Your book is widely read and deeply appreciated, and we are all committed to social psychiatry'. This surprised me, but I found it to be true. The Poles had been taught their psychiatry by the Russians whom they hated. But they had kept up their contact with the French, and the French have a strong social psychiatry movement. The Poles discovered that if they called psychotherapy 'social psychiatry' they could practise it. So, as far as Poland was concerned, 'social psychiatry' was a cover under which to smuggle in psychotherapy, psychoanalysis, Freud, Lacan, the lot!

BB I see you have a $\mathrm{PhD}$.

DC Yes, in Cambridge you can get a PhD for your published works. I was awarded it in 1972 for my writings on social psychiatry.

BB What was the most rewarding period of your professional life?

DC Oh, that is difficult to say. There have been excitements and rewards in all periods. The first period, 
the first nine years at Fulbourn, was an exciting period. The last decade was good too, creating a psychiatric rehabilitation service. There was a lot of fun and excitement then and I think that by the end we had demonstrated a solution to the problems which are bedevilling institutional psychiatry in developed countries all over the place at the moment. What the Americans call 'deinstitutionalisation'. We showed that if you have a wellintegrated, well-knit team of highly motivated staff (not many of them, but good) they can maintain people with long-term psychiatric disabilities in the community and there is no need for hundreds of people to be locked up in dreary asylums, nor for hundreds of lost, pathetic creatures to be wandering the streets of the big cities, raking in the trash cans. However, I must say that the most exciting time was in the sixties when we developed therapeutic communities at Fulbourn Hospital. In opening up the hospital we had been doing what many people in Britain had already done, and we were following in other's footsteps, but with the therapeutic communities we were striking out into completely new country. Nobody had ever taken all the patients from the segregated, locked, disturbed wards of a traditional mental hospital and put them together in one open-door, mixed-sex, therapeutic community. It was a challenging and, at times, terrifying period. We successfully demonstrated that it could be done and that, as a result, people who would otherwise be condemned to a perpetual back ward life could make their way to a degree of independence and free living away from hospital.

But the reason why I say it was exciting was because of what it did for me personally. In the community meetings I was challenged and confronted by the patients and forced to rethink and modify many of the practices of unthinking authority which I had developed in a decade as a medical superintendent. Exciting too was to meet the staff on equal terms and to hear from them something of their complex feelings about the doctors that they had been subjected to over the years. The hostility and the admiration, the envy and the comradeship, the resentment of the medical arrogance and tyranny, and the protection that that very arrogance gave them. I learned an immense amount about myself and my profession during those years. It was a wonderful time.

BB What do you see as the continuing theme of your professional work?

DC The exploration of the social factors in psychiatry. I learned medicine in the early forties when the entire focus was on the individual patient and the things that were wrong inside his body and his mind. The psychiatry which I learned from D. K. Henderson and from Aubrey Lewis was much the samecontinuous, assiduous, devoted examination of the pathology of the person and his mind. Even the psychotherapy of those days was entirely individual. We were not supposed to have any social contacts with our psychotherapy patients, nor even to talk to their relatives.

It is amazing how far we have moved since those days in learning to assess the social dimension and to use it to help the patient. My own personal interest has been social therapy within the institution, the development first of all of open doors and a humane regime, then therapeutic communities and then rehabilitation. There have, however, been many other social developments. There has been the whole development of family therapy which arose directly from the awareness of the social dimension, and of course, the new growth therapies-encounter groups, psychodrama, etc, which are all rooted in the observation that for many people, their inner troubles are caused by their social relationships and the only hope of helping them is by exploring the problem in a social setting.

\section{REFERENCES}

${ }^{1}$ Clark, D. H. (1974) Social Therapy in Psychiatry. Penguin. (Reissued in 1982 by Churchill Livingstone).

${ }^{2}$ Clark, A. J. (1923) Applied Pharmacology. Churchill.

${ }^{3}$ Clark, D. H., Hooper, D. \& Oram, E. G. (1962) Creating a therapeutic community in a psychiatric ward. Human Relations, 15, 123-147.

4. (1984) The development of a psychiatric rehabilitation service. Lancet, ii, 625-627.

5_ (1964) Administrative Therapy. Tavistock.

6 _ \& MYERS, K. (1970) Themes in a therapeutic community. British Journal of Psychiatry, 117, 389-395.

'MYeRs, K. \& ClARK, D. H. (1972) Results in a therapeutic community. British Journal of Psychiatry, 120, 51-58.

\section{Correction}

\section{Membership of the Royal College of Physicians of Ireland}

We were incorrectly informed that Membership of the Royal College of Psychiatrists would give exemption from Part II of the Membership of the Royal College of
Physicians of Ireland. (Bulletin, February 1986, 10, 34) This should have read Part I. 